\title{
Menu Navigation in Mobile Devices Using the Accelerometer
}

\author{
Alejandro Sánchez, Gabriel Villarrubia, Amparo Jiménez, Amparo Casado, \\ Carolina Zato, Sara Rodríguez, Ignasi Barri, Edgar Rubión, Eva Vázquez, \\ Carlos Rebate, José A. Cabo, Joaquín Seco, Jesús Sanz, Javier Bajo, \\ and Juan Manuel Corchado
}

\begin{abstract}
In this article an application for mobile devices is presented. This application uses the accelerometer integrated into the own device to detect certain user movements and use them to navigate through the menus. The application is destined to those users with visual incapacity who need an alternative mechanism for the selection of the different options in the menus.
\end{abstract}

Keywords: accelerometer, menu navigation, mobile devices, disabled people.

\section{Introduction}

During the recent years there is a growing need for adapting the educational environments to the new requirements of the information technologies. One of the

Gabriel Villarrubia $\cdot$ Carolina Zato $\cdot$ Sara Rodríguez $\cdot$ Juan Manuel Corchado Departamento Informática y Automática, Universidad de Salamanca, Salamanca, Spain e-mail: $\{$ gvg, carol_zato, srg, corchado\} @usal.es

Alejandro Sánchez · Amparo Jiménez · Amparo Casado · Javier Bajo

Universidad Pontificia de Salamanca, Salamanca, Spain

e-mail: \{asanchezyu, ajimenezvi, acasadome, jbajope\}@usal.es

Ignasi Barri · Edgar Rubión · Eva Vázquez · Carlos Rebate

INDRA, Spain

e-mail: \{ibarriv, erubion, evazquezdeprada, crebate\} @indra.es

José A. Cabo

Wellness Telecom, Spain

e-mail: jacabo@wtelecom.es

Joaquín Seco · Jesús Sanz

CSA, Spain

e-mail: \{joaquin.seco, jesus.sanz\}@csa.es

P. Vittorini et al. (Eds.): International Workshop on Evidence-Based TEL, AISC 152, pp. 133-140. springerlink.com

(C) Springer-Verlag Berlin Heidelberg 2012 
segments of the population which will benefit with the advent of systems based on Ambient Intelligence will be the elderly and people with disabilities [6], contributing to improve their quality of life 7. Ambient Intelligence evolves from the ubiquitous computing 3 , and constitutes the most promising technological approach to meet the challenge of developing strategies in dependency environments [8].

This work presents an innovative method, based on the Ambient Intelligence (AmI) paradigm [4, 7], for formal teaching of languages oriented to disabled people, specifically, with visual disabilities. In this way, it is proposed a method to facilitate the integration of disabled people in the information society. The special characteristics of disabled people require new solutions, since the learning methods used in early ages are most of the times not appropriated for this sector of the society. It is necessary to investigate in new techniques and methods to satisfy the learning needs of the elderly people.

This paper focuses in the combination of the new information technologies along with the traditional teaching. In this way it will be possible to combine the advantages of traditional teaching and the advantages of the mobile devices. It will be necessary to upgrade the systems of evaluation/accreditation to assess the knowledge or skills acquired during the learning process. To achieve this objective, we propose the use of mobile devices, intelligent systems and wireless communications.

The rest of the paper is structured as follows: Next section introduces the problem that motivates most of this research. Section 3 presents the proposed application for mobile devices used by visual disabled people. Finally, section 4 explains some conclusions obtained.

\section{Background}

At the moment, numerous technological advances exist to facilitate the daily workings to the disabled or elderly users, adapting the technology to their needs. For it, in recent years, the use of smartphones is growing due to the wide range of possibilities that these offer. This type of mobile telephones includes a series of complements like a-gps, radio, digital compass or the accelerometer.

There is an ever growing need to supply constant care and support to the disabled and elderly and the drive to find more effective ways to provide such care has become a major challenge for the scientific community [3]. During the last three decades the number of Europeans over 60 years old has risen by about $50 \%$. Today they represent more than $25 \%$ of the population and it is estimated that in 20 years this percentage will rise to one third of the population, meaning 100 millions of citizens [3]. In the USA, people over 65 years old are the fastest growing segment of the population [1] and it is expected that in 2020 they will represent about 1 of 6 citizens totaling 69 million by 2030. Furthermore, over $20 \%$ of people over 85 years old have a limited capacity for independent living, requiring continuous monitoring and daily care [2]. Some estimations of the World Health Organization show that in 2025 there will be more than 1000 
million people aged over 60 in the world, so if this trend continues, by 2050 will be double, with about the $80 \%$ concentrated in developed countries [9].

Education is the cornerstone of any society and it is the base of most of the values and characteristics of that society. The new knowledge society offers significant opportunities for AmI applications, especially in the fields of education and learning [8]. The new communication technologies propose a new paradigm focused on integrating learning techniques based on active learning (learning by doing things, exchange of information with other users and the sharing of resources), with techniques based on passive learning (learning by seeing and hearing, Montessori, etc.) [5]. While the traditional paradigm, based on a model focused on face to face education, sets as fundamental teaching method the role of the teachers and their knowledge, the paradigm based on a learning model highlights the role of the students. In this second paradigm the students play an active role, and build, according to a personalized action plan, their own knowledge. Moreover, they can establish their own work rhythm and style. The active methodology proposes learning with all senses (sight, hearing, touch, smell and taste), learn through all possible methods (school, networking, etc.), and have access to knowledge without space or time restrictions (anywhere and at any time).

There are different studies that have used the Ambient Intelligence to facilitate learning. In [3], Bomsdorf shows the need to adapt intelligent environments to changes depending on the educational context and the characteristics of users. Morken et al. [9] analyze the characteristics of intelligent environments for learning. They focus on the role of mobility in educational environments and the role that acquire the mobile devices. Naismith et al. [10] conducted a detailed study describing the role of mobile devices in education, analyzing the characteristics of the devices and their capacity for learning in educational environments. All these approaches are focused on the role of learning in Ambient Intelligence environments, but none of them is oriented on learning for dependents or elderly people. The following section presents a multiagent architecture that facilitates learning methodology using an active through mobile devices.

\subsection{Operation of an Accelerometer}

An accelerometer is an electromechanical device that measures the forces of the acceleration [24]. The accelerometer provides new possibilities of interaction with the users, allowing to place orders by movements. These devices belong to category MEMS (Micro Electro-Mechanical Systems), which are a type of electromechanical devices, constructed normally with remodeled polycrystalline silicon.

The forces that measure can be:

- Static forces: Gravity towards the Earth center

- Dynamic forces: Movement or the vibration of the devices 
The operation of the accelerometer is relatively simple. First of all, it measures the static acceleration of the gravity, obtaining therefore the angle of the device with respect to the Earth. Next, it measures with the sensors of dynamic acceleration. The movement of the accelerometer can be analyzed in the three dimensions.

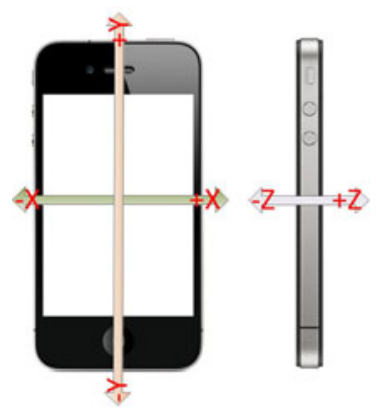

Fig. 1 Dimension of the operation in accelerometers.

\subsection{Devices with Accelerometer}

There are a great amount of devices that own an accelerometer within them. It surprises now that the first accelerometers were not those included in the devices of mobile telephony, they were used previously. One of the first uses of this apparatus was in hard disks. Its function consisted on measuring the vibrations and inclination of the device when changing of internal disc and thus to try that there were not problems of internal collisions.

Another use of the accelerometer was in the last generation of games consoles. Nintendo released the novel Wii. This game console broke the concepts previously established, since the controls are not connected, they communicated via infrared, having in addition, an accelerometer to catch the movements of the user. In this section, the mobile telephony can be also included, since the majority of devices in this scope, only uses it as part of entertainment applications.

Finally, a research group of the Pontifical University of Salamanca carried out a project, called AESCOLAPIUS, for the construction of a wheelchair able to move using the different functionalities that smartphones offer. Within the scope our work the most interesting functionality is the offered by the accelerometer, since the chair reacts to the movements made with the device [11].

\section{Developed Application}

The application is based on a navigation menu using the accelerometer available in many mobile devices, especially in the iPhone platform. This application may solve the problems that visually impaired people have while using a menu with different options. Cutting-edge devices have touch screens and it's impossible for them to identify where they are pressing. 
A movement recognition algorithm has been created in order to collect all data necessary for the successful operation of the system.

The designed algorithm is based on two distinct aspects: the current position of the device and its previous position. The time gap used between both measurements is one second, being this gap fully configurable. After multiple tests, it was concluded that a shorter gap affects the stability of the application, since the values of the accelerometer are constantly changing. As seen above, the device is able to move in three different axes, being the variation in each of them a value between 1 and -1 . Next, movements, which are taken into account in the algorithm, will be defined.

\section{Central Position}

This will be fulfilled when previous $X$ has values between 0,2 and $-0,2$ and present $\mathrm{X}$ has values between 0,2 and -0.2

\section{Movements to the Right}

A turn limit has been settled down to detect when a movement to the right takes place, this movement is necessary to navigate through one option of the menu. This limit is the previous position plus a turn rank, which has settled down that is needed to turn at least $45^{\circ}$ towards the right. This movement needs that the device comes from the position centered in $\mathrm{X}$-axis.

This will be fulfilled when present $X$ is major that previous $X$ the 0,5 and device is centered more in $\mathrm{X}$.

\section{Cancelation of an Option}

The elimination of an option to be able to choose another one of the menu, is carried out by a left turn of the device, starting the movement from the vertical position. If an option is eliminated, doing a movement to the right the following option of the menu is selected.

This will be fulfilled when previous $\mathrm{X}$ is major that present $\mathrm{X} 0,5$ (value limits) and we are trims in $\mathrm{X}$ more.

\section{Access control of an Option}

The selection of an option is the fundamental pillar of the algorithm, since the values taken with the previous functions are used. The access to an option of the menu is carried out through movements on z-axis (movements of back forwards or vice versa). In order to enter an option, this need to be previous selected by movements to the right and left, and then, make a movement with the device to backwards.

The access to an option will be fulfilled when we are centered in $\mathrm{X}$ and $\mathrm{Z}$ axis and we have chosen an option previously (without cancelled it) and that previous value $\mathrm{Z}$ is major that present $\mathrm{Z}$ plus 0,5 (value limits).

\section{Return to the Previous Menu}

The exit to a previous menu will allow the user to leave a screen when it does not need it, and to return to a previous menu. 
The exit will be fulfilled when we are centered in the $\mathrm{X}$ and $\mathrm{Z}$ axis and that present value $\mathrm{Z}$ is major that previous $\mathrm{Z}$ plus 0,5 (value limits)

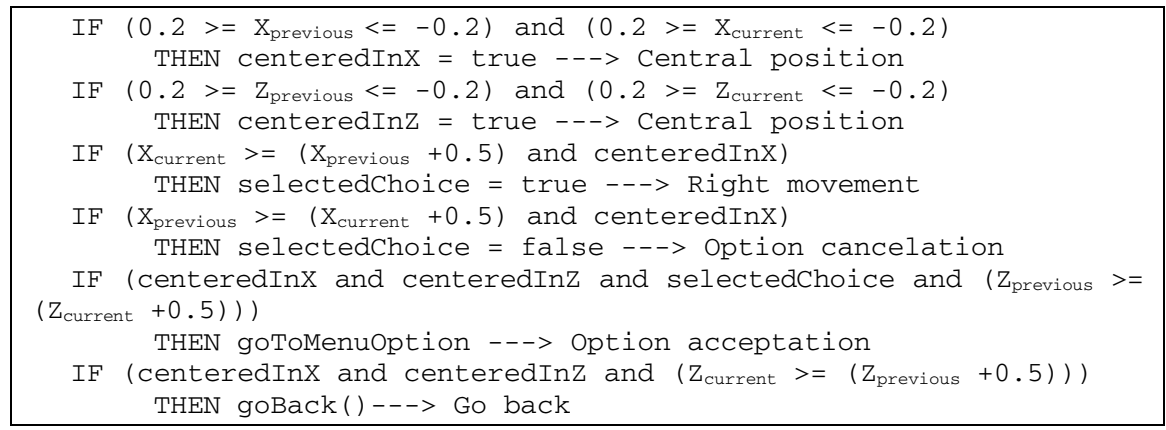

Fig. 2 Algorithm for controlling the movements
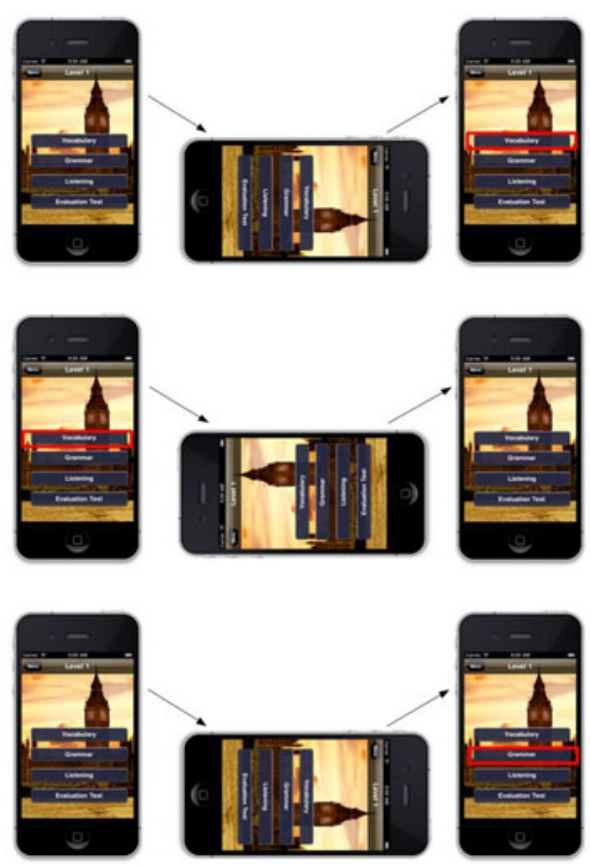

Fig. 3 Operation example 


\section{Conclusions}

The project focus on the learning of languages through mobile telephone, in our case iPhone, and more in particular, oriented to people with visual disability.

This paper has presented a new method for teaching languages to disabled people, using techniques of Ambient Intelligence and mobile devices. The new algorithm, based on the use of the accelerometer, presented in this paper provides an active learning through simple and intuitive interfaces, installed on mobile devices and movement recognition. This requires the integration of intelligent algorithms with innovative strategies of teaching languages and mobile devices. In this way we have obtained:

- An active method of teaching and learning of languages for people with visual disabilities.

- An interaction system based on the AmI paradigm for language education.

- The obtained language learning system was adapted to be executed on mobile devices, facilitating the adaptation to the needs of the dependent and elderly people.

The system has been developed under the framework of the AZTECA project and has been tested by the visually disabled users involved in this project. The users have remarked the potential possibilities of the interaction method. However, it is still necessary to perform a more general evaluation with final users.

Acknowledgements. This project has been supported by the Spanish CDTI. Proyecto de Cooperación Interempresas. IDI-20110343, IDI-20110344, IDI-20110345, and the MICINN TIN 2009-13839-C03-03 project. Project supported by FEDER funds.

\section{References}

1. Anastasopoulos, M., Niebuhr, D., Bartelt, C., Koch, J., Rausch, A.: Towards a Reference Middleware Architecture for Ambient Intelligence Systems. In: ACM Conference on Object-Oriented Programming, Systems, Languages, and Applications (2005)

2. Angulo, C., Tellez, R.: Distributed Intelligence for smart home appliances. In: Tendencias de la Minería de Datos en España, Red Española de Minería de Datos, Barcelona, España (2004)

3. Bajo, J., Corchado, J.M., de Paz, Y., de Paz, J.F., Rodríguez, S., Martín, A., Abraham, A.: SHOMAS: Intelligent Guidance and Suggestions in Shopping Centres. Applied Soft Computing 9(2), 851-862 (2009)

4. Bajo, J., de Paz, J.F., de Paz, Y., Corchado, J.M.: Integrating Case-based Planning and RPTW Neural Networks to Construct an Intelligent Environment for Health Care. Expert Systems with Applications 36(6), Part 2, 5844-5858 (2009)

5. Brown, T.H.: Beyond constructivism: Exploring future learning paradigms. In: Education Today, vol. (2). Aries Publishing Company, Thames (2005) 
6. Carretero, N., Bermejo, A.B.: Inteligencia Ambiental. CEDITEC: Centro de Difusión de Tecnologías. Universidad Politécnica de Madrid, España (2005)

7. Echt, K.V.: Designing web-based health information for older adults: visual considerations and design directives. In: Morrell, R.W. (ed.) Older Adults, Health Information and the World Wide Web, pp. 61-87. Lawrence Erlbaum Associates (2002)

8. Friedewald, M., Da Costa, O.: Science and Technology Roadmapping: Ambient Intelligence in Everyday Life (AmI@Life). Working Paper. Institute for Prospective Technology Studies IPTS, Seville (2003)

9. Kurniawan, S.H., King, A., Evans, D.G., Blenkhorn, P.L.: Personalising web page presentation for older people. Interacting with Computers 18, 457-477 (2006)

10. Naismith, L., Lonsdale, P., Vavoula, G., Sharples, M.: Futurelab Literature Review in Mobile Technologies and Learning. Technical Report for Futurelab (2004), http://www. futurelab.org.uk/research/reviews/reviews_11_an d12/11_01.htm

11. Berjón, R., Mateos, M., López, A., Muriel, I., Villarrubia, G.: Alternative humanmachine interface system for powered wheelchairs. In: Corchado, J.M., Bajo Pérez, J., Hallenborg, K., Golinska, P., Corchuelo, R. (eds.) Trends in Practical Applications of Agents and Multiagent Systems. AISC, vol. 90, pp. 307-315 (2011)

12. Bao, M.H.: Micro Mechanical Tansducers: Pressure Sensors, Accelerometers and Gyroscopes. Handbook of Sensors and Actuators, vol. 8. Elsevier Editions 